\title{
Improvement of the Lubrication Performance of RBD Palm Stearin as an Alternative Lubricant under Different Sliding Speeds
}

\author{
Nurul Farhanah Azman* - Syahrullail Samion \\ University of Technology Malaysia, Faculty of Mechanical Engineering, Malaysia
}

\begin{abstract}
Vegetable oils have gained global att-ention to be used as an alternative lubricant to reduce the dependency on natural resources of petroleumbased lubricants due to concern over environmental problems. In this study, a refined, bleached and deodorized (RBD) palm stearin was chosen as the base lubricant, and its lubrication performance was investigated using a pin-on-disk tribotester. A zinc dialkyl-dithiophosphate (ZDDP) additive in concentrations of $1 \mathrm{wt} \%, 3 \mathrm{wt} \%$ and $5 \mathrm{wt} \%$ was blended with RBD palm stearin to improve the lubrication performance of the base lubricant. Commercial semi-synthetic oil (SAE15W50) was used for comparison purposes. The experiments were conducted under various sliding speeds $\left(1.5 \mathrm{~ms}^{-1}, 2.5 \mathrm{~ms}^{-1}\right.$ and $\left.3.5 \mathrm{~ms}^{-1}\right)$ under normal force of $9.81 \mathrm{~N}$ for an hour. The lubrication performance of the tested lubricants was presented by the coefficient of friction, wear scar diameter, wear rate, surface roughness and wear worn surface of the pin specimen. The results show that an increase in ZDDP concentrations has improved the lubrication performance of the RBD palm stearin. RBD palm stearin with 5 wt\% ZDDP additive shows a smaller coefficient of friction than that of SAE15W50, but creates a slightly larger wear scar diameter and wear rate.
\end{abstract}

Keywords: RBD palm stearin, ZDDP, coefficient of friction, wear rate

Highlights

- The lubrication performance of RBD palm stearin and its formulation were evaluated using a pin-on-disk tribotester.

- The influences of ZDDP additive concentrations on the lubrication performance of RBD palm stearin were determined.

- The results indicate that an increase in ZDDP concentrations has improved the lubrication performance of the RBD palm stearin.

- RBD palm stearin blended with 5 wt\% of ZDDP shows an excellent friction-reducing performance than SAE15W50 does.

\section{INTRODUCTION}

The majority of the lubricants currently in use are petroleum-based lubricants [1]. In 2004, approximately 37.4 million tonnes of lubricants [2], with 12 million tons of lubricant waste being released into the environment, were used [3]. Petroleumbased lubricants have a very high level of toxicity and are non-biodegradable which is harmful to the environment. Regarding environmental problem issues, vegetable oils have gained global attention to be used as an alternative lubricant. The use of these renewable resources will reduce the dependency on natural resources of petroleum-based lubricants [4].

Vegetable oils are the most suitable candidates to replace petroleum-based lubricants because they have many advantages, such as being renewable, biodegradable, non-toxic and contributing zero pollution [5]. Despite having environmental advantages, vegetable oils have limited oxidative stability and thermal stability. The presence of unsaturated fatty acid $(\mathrm{C}=\mathrm{C})$ makes the vegetable oils easily oxidized due to the existence of bis-allylic protons between two double bonds that is highly susceptible to radical attack [6]. The higher the number of double bonds or the higher the level of unsaturation value, the higher the tendency of vegetable oils to oxidize. Whereas, a higher level of saturation value causes poor low-temperature properties, including cloudiness, precipitation, poor flowability and solidification at low temperatures [6]. The formulation of vegetable oils with commercial additives will probably help in the improvement of the lubrication performance of vegetable oils as lubricants.

Previous research had shown that zinc dialkyldithiophosphate (ZDDP) improves the lubrication performance of vegetable oils. Jayadas et al. investigated the lubrication performance of pure coconut oil with and without the ZDDP additive [7]. Among other vegetable oils, coconut oil has much better oxidative and thermal stability due to its high degree of saturated fatty acid composition. They monitored the evaluation of lubrication performance using a four-ball tester and test rig. The results were compared with SAE20W50 commercial mineral oil. Their analysis revealed that the wear scar diameter (WSD) of pure coconut oil is larger than that of SAE20W50, although the coefficient of friction (COF) of coconut oil is much smaller. This is attributed to the continuous removal of metallic soap film during 
surface sliding, and it reacts chemically with metal surfaces resulting in poor protection against wear. This metallic soap film has low shear strength, resulting in low COF. However, when $2 \mathrm{wt} \%$ of ZDDP additive is added into the coconut oil, it improves both wear and friction performance. Sulphur and phosphorus content in ZDDP will form an iron sulphide and iron phosphide layer that is low in shear strength, hence preventing rapid oxidation and wear. ZDDP also acts as an antioxidant agent to prevent oxide formation on the metal surface.

Cheenkachorn discovered that the addition of $1 \%$ ZDDP in soybean oil, epoxidized soybean oil, and high oleic soybean oil significantly reduces the coefficient of friction especially at lower temperatures [8]. It is thought that the desorption rate of the additive on the surface is higher than the adsorption rate at higher temperatures. The addition of additive effectively protects the rubbing surfaces since it can form a thin protective film with the attachment of a polar head to the metal and the non-polar ends can form a molecular layer. Mahipal et al. investigated the effectiveness of ZDDP as an additive in Karanja oil in terms of friction and wear performance [9]. Karanja oil added with 2 $\mathrm{wt} \% \mathrm{ZDDP}$ is the optimum concentration in reducing both COF and WSD. ZDDP effectively reduces friction and wear with the formation of the protective film, the elimination of corrosive peroxides and the disintegration of hard and abrasive iron oxides. However, it was found that further increases in ZDDP concentrations above $2 \mathrm{wt} \%$ cause an increase in friction and wear. This is due to excess zinc adsorption on the contact surface that will increase the friction, while the heavier structure of ZDDP will be attached to the metal surface resulting in larger WSD.

In this research, refined, bleached, and deodorized (RBD) palm stearin (PS) was used as a base lubricant, and its lubrication performance was evaluated using a pin-on-disk tribotester. ZDDP was selected because it is the most commonly used and cost effective multifunctional additive in engine oil formulation. According to Girotti et al., the typical composition of ZDDP in engine oil formulation is $3 \%$, which is present in antioxidant and antiwear additives [10]. The effectiveness of ZDDP additive in PS was also investigated in terms of their lubrication performance. The results were compared with commercial semisynthetic oil (SAE15W50). In addition, the effect of sliding speeds condition on the lubrication performance is also present.

\section{METHODS AND EXPERIMENTAL}

Refined, bleached and deodorized (RBD) palm stearin was used in this research with a viscosity $38.01 \mathrm{~mm}^{2} \mathrm{~s}^{-1}$ at $40{ }^{\circ} \mathrm{C}$ and $8.55 \mathrm{~mm}^{2} \mathrm{~s}^{-1}$ at $100{ }^{\circ} \mathrm{C}$, a viscosity index of 212.56, free fatty acid (as palmitic) $0.04 \%$ and an iodine value of 35.2. Zinc dialkyldithiophosphate (ZDDP) additive was commercially purchased and blended at a concentration of $1 \mathrm{wt} \%, 3$ $\mathrm{wt} \%$ and $5 \mathrm{wt} \%$ with RBD palm stearin to improve its lubrication performance. Commercial semi-synthetic oil (SAE15W50) was used for comparison purposes with a viscosity of $112.9 \mathrm{~mm}^{2} \mathrm{~s}^{-1}$ at $40{ }^{\circ} \mathrm{C}$ and 20.9 $\mathrm{mm}^{2} \mathrm{~s}^{-1}$ at $100{ }^{\circ} \mathrm{C}$, and a viscosity index of 211.89 . RBD palm stearin has lower kinematic viscosity than SAE15W50 because it contains unsaturated fatty acid, and a high level of unsaturation results in lower kinematic viscosity [11]. The density of RBD palm stearin and SAE15W50 is $0.87 \mathrm{gcm}^{-3}$ and $0.88 \mathrm{gcm}^{-3}$, respectively.

Lubrication performance of the tested lubricants was carried out using a pin-on-disk tribotester (pure aluminium A1100 vs. SKD11 tool steel disk) in accordance to ASTM G99. A hemispherical end pin-on-disk tribotester uses a nonconformal contact, which is suitable for such applications as wheels, bearings, traction drives, gears and cams [12]. Furthermore, nonconformal contact can avoid alignment problem during the test. This is because even small misalignments between the surfaces can result in uneven distribution of contact pressure and uneven trapping of wear debris or lubricants [13]. The selection of material for the pin and disk used in the present research to match prior experiments conducted by other researchers [14]. In addition, aluminium is a lightweight metal that has been widely used in automotive applications due to the need for improved fuel economy [15]. The material pair also was chosen to obtain most of the significant wear for the softer A1100 pin material, as compared to the harder SKD11 disk which is highly wear resistant. The scheme of the tribotester was presented in Fig. 1 which shows a stationary pin was in contact with the disk at a constant vertical force. The experiment ran at an applied load of $9.81 \mathrm{~N}$ for an hour of test duration with sliding speeds of $1.5 \mathrm{~ms}^{-1}, 2.5 \mathrm{~ms}^{-1}$ and $3.5 \mathrm{~ms}^{-1}$ at room temperature. A small amount of lubricant (2.5 $\mathrm{ml}$ ) was placed on the disk surface, and the disk was designed to have a groove to prevent the lubricant from flowing out during the rotation of the disk. The disk was rotated at a specified speed creating a sliding contact, and frictional force sensor will measure the friction force. The data was presented in a data 


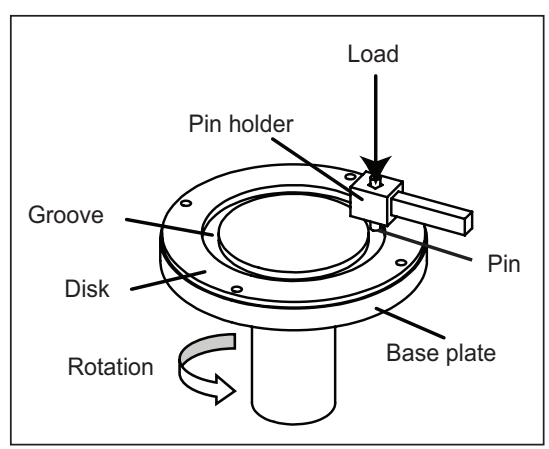

(a)

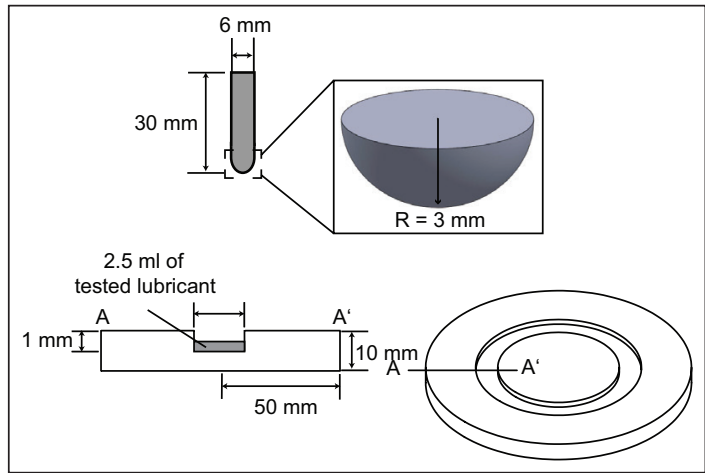

(b)

Fig. 1. a) Schematic diagram of pin-on-disk and b) Geometry of the pin and disk

acquisition system, and then the friction force value was used to calculate the coefficient of friction (COF). The COF was taken as a measure of the frictionreducing performance of the tested lubricants.

The mean contact Hertz pressure was calculated as in Eq. (1) [16].

$$
\bar{p}=\frac{1}{\pi}\left(\frac{4 E^{\prime}}{3 R}\right)^{2 / 3} P^{1 / 3}
$$

where $P$ is the normal load, $R$ is the radius of curvature of the hemispherical end of the pin, $E$ ' is the effective elastic modulus which is equal to $\left(\left(1-v_{1}^{2}\right) / E_{1}+\left(1-v_{2}^{2}\right) / E_{2}\right)^{-1}$, where $E_{1}$ and $v_{1}$ denote elastic modulus and Poisson's ratio for aluminium A1100 pin, $E_{2}$ and $v_{2}$ denote elastic modulus and Poisson's ratio for the tool steel SKD11 disk. Given that $E_{1}=75 \mathrm{GPa}, v_{1}=0.34, E_{2}=212.8 \mathrm{GPa}$ and $v_{2}=$ 0.28 , the effective elastic modulus $E^{\prime}=61.69 \mathrm{GPa}$; thus, mean contact Hertz pressure, $\bar{p}$ is $0.62 \mathrm{GPa}$.

The minimum film thickness was calculated using EHL equations as in Eq. (2) to determine the lubrication regime of a tribosystem.

$$
H_{\min }=3.63 U^{0.68} G^{0.49} W^{-0.073}\left(1-e^{-0.68 k}\right),
$$

where $U$ is the dimensionless speed parameter $\left(U=\left(\eta_{0} V\right) /\left(E^{\prime} R_{x}\right)\right.$ ), where $\eta_{0}$ is the dynamic viscosity at $27^{\circ} \mathrm{C}, V$ is the surface velocity of the disk, $E^{\prime}$ is the effective modulus of elasticity, $R_{x}$ is the curvature of the pin. $G$ is the dimensionless materials parameter $\left(G=\alpha E^{\prime}\right)$, where $\alpha$ is the viscosity-pressure coefficient. $W$ is the dimensionless load parameter ( $W=F /\left(E^{\prime} R_{x}^{2}\right)$ ) where $F$ is the normal load exerted on the pin, and $k$ is the elliptical parameter $\left(k=R_{y} / R_{x}\right.$ ) where $R_{y}$ is the elliptical contact in the $y$-direction and $R_{x}$ is the elliptical contact in $x$-direction [17] and [18].
After calculating the minimum film thickness, $h_{\min }$, Eq. (3) the lubrication regime can be calculated by determining the dimensionless film parameter, also called lambda ratio, seen in Eq. (4).

$$
\begin{aligned}
& h_{\min }=H_{\min } \cdot R_{x}, \\
& \lambda=\frac{h_{\min }}{\sqrt{R_{q 1}^{2}+R_{q 2}^{2}}},
\end{aligned}
$$

where $R_{q 1}$ and $R_{q 2}$ are the root mean square roughness of the two solid surfaces. In the present study, the value of rms roughness of pin and disk are $0.43 \mu \mathrm{m}$ and $0.35 \mu \mathrm{m}$ respectively. The range of $\lambda$ for the lubrication regimes are boundary lubrication $\lambda \leq 1$; mixed lubrication $3>\lambda>1$ and full film lubrication $\lambda \geq 3[18]$.

Information for geometry and calculated lubricant constants are given in Table 1. The dynamic viscosity, $\eta_{0}$ at $27^{\circ} \mathrm{C}$ for each tested lubricant is given by $\eta_{(\mathrm{SAE} 15 \mathrm{~W} 50)}=0.172 \mathrm{~Pa} \cdot \mathrm{s}$, and $\eta_{(\mathrm{RBD} \text { palm stearin })}=$ $0.152 \mathrm{~Pa} \cdot \mathrm{s}$. The calculated minimum film thickness and lubricant regime for the tested lubricants at speed varying from $1.5 \mathrm{~ms}^{-1}$ to $3.5 \mathrm{~ms}^{-1}$ are shown in Table 2 .

Table 1. Geometry and calculated lubricant constants

\begin{tabular}{lc}
\hline$R_{x}$ & $0.003 \mathrm{~m}$ \\
\hline$E^{\prime}$ & $6.169 \times 10^{10} \mathrm{~Pa}$ \\
\hline$k$ & 1.0339 \\
\hline$\alpha$ & $2.1 \times 10^{-8} \mathrm{~Pa}$ \\
\hline$G$ & 1279 \\
\hline
\end{tabular}

The anti-wear performance of the tested lubricants was measured by taking the wear scar diameter (WSD) and calculating the wear rate. The WSD of the pin was measured by using an optical microscope to calculate the wear volume $(V)$ as in Eq. 
(5) [19], then the value was used to calculate the wear rate as in Eq. (6) [20].

Table 2. Calculated minimum film thickness and lubricant regime at speed varying from $1.5 \mathrm{~ms}^{-1}$ to $3.5 \mathrm{~ms}^{-1}$

\begin{tabular}{lcccc}
\hline Lubricants & $\begin{array}{c}\text { Speed } \\
{\left[\mathrm{ms}^{-1}\right]}\end{array}$ & $\begin{array}{c}h_{\min } \\
{[\mu \mathrm{m}]}\end{array}$ & $\lambda$ & Lubrication regime \\
\hline \multirow{3}{*}{ SAE15W50 } & 1.5 & 0.3869 & 0.6979 & Boundary lubrication \\
\cline { 2 - 5 } & 2.5 & 0.5477 & 0.9878 & Boundary lubrication \\
\cline { 2 - 5 } & 3.5 & 0.6884 & 1.2417 & Mixed lubrication \\
\hline \multirow{3}{*}{$\begin{array}{l}\text { RBD palm } \\
\text { stearin }\end{array}$} & 1.5 & 0.3557 & 0.6416 & Boundary lubrication \\
\cline { 2 - 5 } & 2.5 & 0.5035 & 0.9081 & Boundary lubrication \\
\hline
\end{tabular}

$$
V=\frac{\pi r^{4}}{4 R}
$$

where; $r$ is the radius of pin wear scar [mm], and $R$ is original pin radius [mm].

$$
k=\frac{V}{S F},
$$

where $k$ is the wear rate $\left[\mathrm{mm}^{3} \mathrm{~N}^{-1} \mathrm{~m}^{-1}\right], V$ is the volume of material removed by wear $\left[\mathrm{mm}^{3}\right], S$ is the sliding distance [m], and $F$ is the applied force [N].

Surface roughness and wear worn surfaces of the pin specimen were obtained using a surface profiler and high-resolution optical microscope. The present study only considered the arithmetic mean surface roughness $(R a)$ value for analysis purposes since this is a good parameter in which the conditions are always the same. To ensure there was no excess oil on the pin surface, the pins were cleaned with acetone after each test.

\section{RESULTS AND DISCUSSION}

\subsection{Friction-Reducing Performance}

The experiments were conducted at different sliding speeds, at $1.5 \mathrm{~ms}^{-1}, 2.5 \mathrm{~ms}^{-1}$ and $3.5 \mathrm{~ms}^{-1}$, respectively, in order to study the friction-reducing performance of RBD palm stearin with and without a ZDDP additive. The pin-on-disk tribotester was run at $9.81 \mathrm{~N}$ for an hour. A ZDDP additive of $1 \mathrm{wt} \%, 3$ $\mathrm{wt} \%$, and $5 \mathrm{wt} \%$ was added into RBD palm stearin to improve its lubrication performance. The frictionreducing performance of the RBD palm stearin with and without the ZDDP additive was compared to a commercial semi-synthetic oil (SAE15W50). The coefficient of friction (COF) was calculated by dividing the frictional force by the normal load and plotted against the sliding speed in Fig. 2.
It can be seen from the graphs that the COF increased with an increase in the sliding speed, except for PS+5 $\mathrm{wt} \%$ ZDDP. It was found that RBD palm stearin (PS) had a significantly larger COF in comparison to SAE15W50. It is thought that the high content of unsaturated fatty acid in PS may have contributed to the higher COF. It is widely known that vegetable oils with a high content of unsaturated fatty acid have a low resistance to oxidative degradation. According to Joseph and Sharma, vegetable oils follow the same free radical oxidation as hydrocarbon mineral oil does, but it oxidizes at a faster rate [21]. As has been noted, PS, being highly susceptible to oxidation, is unable to provide a stable lubricant film to prevent metal surfaces from coming into contact with each other, hence increasing the friction. Additionally, PS did not seem to be effective in reducing friction because it remained in a semi-solid state at room temperature when the experiment was being conducted. It is widely accepted that a higher viscosity will generate a thicker tribofilm, hence providing better lubrication performance. However, in this case, the viscosity of PS was too thick, thus resulting in greater heat generation. The heat generated eventually raised the rate of oxidation, thus generating more wear debris on the metal surface and the oxidation of the debris will eventually raise the COF [22].

The figure also showed that an increase in the additive concentration improved the frictionreducing performance of PS. It is clear from Fig. 2 that the friction-reducing performance of $\mathrm{PS}+5 \mathrm{wt} \%$ ZDDP (0.039) was comparable to that of SAE15W50 $(0.035)$ at a low sliding speed, while at $3.5 \mathrm{~ms}^{-1}$, PS+5 $\mathrm{wt} \%$ ZDDP (0.036) gave a better friction-reducing performance than SAE15W50 (0.067) did. It was evident that the ZDDP was responsible for protecting the PS from oxidation, thus resulting in a better friction-reducing performance by the lubricating oil. ZDDP has long been recognized for its ability as an antioxidant to resist oxidation degradation. ZDDP functions both as a radical scavenger and as a peroxide decomposer [23]. It inhibits the formation of free radicals by breaking the chains that react with the radicals in order to form stable compounds that prevent further propagation of the free radical chain. ZDDP also reacts with hydroperoxide molecules during the oxidation process to prevent the formation of peroxy radicals. The presence of organic molecules such as zinc, phosphorus, and sulphur in ZDDP make it a powerful antioxidant since these organic molecules bond to the surface of the metal to form a protective coating. Sulphur and phosphorus compounds will also 
react with metal surfaces to form a low shear strength film, thus reducing the COF [24].

Furthermore, it can be seen in Fig. 2 that the friction behaviour of PS+5 wt $\%$ ZDDP was not significantly affected by the sliding speed, where the average coefficient of friction of the various sliding speeds was 0.037 , which indicated the best friction-reducing performance. This suggests that at a concentration of $5 \mathrm{wt} \%$, the ZDDP provided a lubricant film on the surface of the metal and this film was maintained at various sliding speeds, thereby maintaining the COF. The ZDDP was dominant at this concentration and acted as a "friction modifier" in PS. The ZDDP additive in vegetable oil exhibited a good friction-reducing ability in comparsion to vegetable oil alone because the chemical adsorption of the ZDDP additive to the metal surface was stronger than the physical adsorption of vegetable oil on the surface [8].

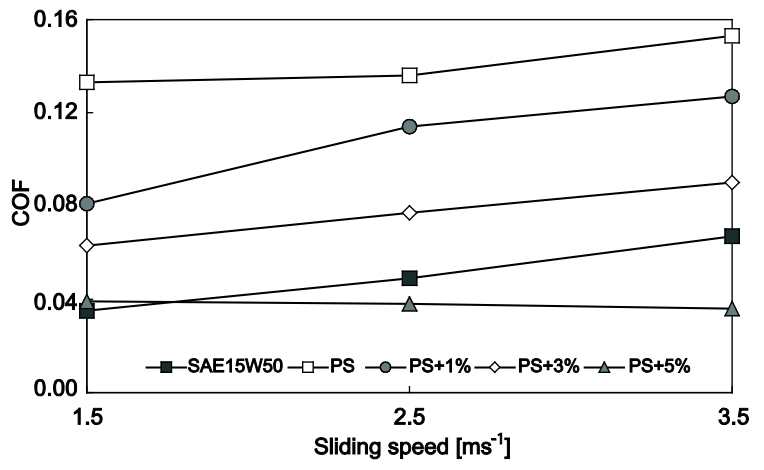

Fig. 2. Effects of sliding speed on coefficient of friction

\subsection{Anti-Wear Performance}

The wear scar diameter (WSD) of the pin surfaces was measured using an optical microscope, and the values were plotted against the sliding speed, as shown in Fig. 3. The wear rate was also calculated using Eq. (2) and the data were tabulated in Table 3. Fig. 3 shows no clear trend with regard to the WSD at different sliding speeds, but when calculating the wear rate of the pin, as shown in Table 3 , it was indicated that the wear rate decreased with an increase in the sliding speed. Fig. 2 shows that the COF increased with an increase in the sliding speed, but the wear rate is decreasing (see Table 3). An increase in the sliding speed usually leads to heat generation in the contact region, where an increase in temperature will result in more oxidation. Wear debris will form during abrasion, where oxidation of the debris will eventually raise the COF [22]. However, a rise in temperature will cause the formation of an oxide layer. It was observed in some previous research that this oxide film offers a certain amount of protection from wear [25] and [26]. This is possibly the reason that an increase in sliding speed will reduce the wear rate.

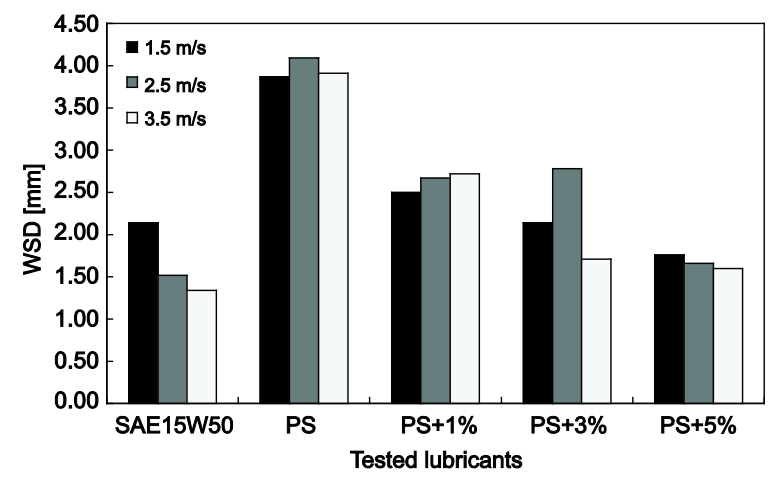

Fig. 3. Effects of sliding speed on wear scar diameter (WSD)

Table 3. Wear rate of the tested lubricants under different sliding speeds

\begin{tabular}{lccc}
\hline \multirow{2}{*}{ Tested lubricants } & \multicolumn{3}{c}{ Wear rate $\times 10^{-5}\left[\mathrm{~mm}^{3} \mathrm{~N}^{-1} \mathrm{~m}^{-1}\right]$} \\
\cline { 2 - 4 } & $1.5 \mathrm{~ms}^{-1}$ & $2.5 \mathrm{~ms}^{-1}$ & $3.5 \mathrm{~ms}^{-1}$ \\
\hline SAE15W50 & 0.65 & 0.10 & 0.04 \\
\hline PS & 6.93 & 5.19 & 3.09 \\
\hline PS+1 wt\% ZDDP & 1.21 & 0.94 & 0.73 \\
\hline PS+3 wt\% ZDDP & 0.65 & 1.11 & 0.11 \\
\hline PS+5 wt\% ZDDP & 0.30 & 0.14 & 0.09 \\
\hline
\end{tabular}

It can be seen that the addition of $1 \mathrm{wt} \%$ ZDDP into the PS significantly reduced the wear rate of the specimen pin. This result indicated that ZDDP effectively reduced the wear. A further increase in the ZDDP concentration slightly reduced the wear rate of the specimen pin. The anti-wear performance of PS+5 wt $\%$ ZDDP $(1.76 \mathrm{~mm})$ was comparable to that of SAE15W50 $(2.14 \mathrm{~mm})$ at a low sliding speed. However, PS $+5 \mathrm{wt} \%$ ZDDP $(1.60 \mathrm{~mm})$ created a slightly larger WSD than SAE15W50 (1.34 mm) at a sliding speed of $3.5 \mathrm{~ms}^{-1}$.

PS showed a larger WSD and wear rate in comparison to SAE15W50 due to its high content of unsaturated fatty acid, which resulted in poor oxidative stability due to the $\mathrm{C}=\mathrm{C}$ bonds that functioned as active sites for the oxidation reactions. The oxidation of vegetable oil will increase the viscosity of the oil, thereby forming numerous deposits in the oil. These results correspond with the findings by de Almeida et al., where the use of refined palm oil at ambient temperature caused the formation of many deposits due to the high viscosity [27]. The addition of ZDDP to the PS reduced the WSD and wear rate of the 
specimen pin. This was attributed to the protection of the lubricant against oxidation and preventing the formation of deposits in the oil. The addition of $5 \mathrm{wt} \%$ ZDDP to PS provided good protection against wear as it possessed anti-wear properties comparable to that of SAE15W50.

\subsection{Surface Analysis}

\subsubsection{Surface Roughness Characteristics}

Fig. 4 shows the arithmetic mean deviation of the surface roughness $(R a)$ against the sliding speed. The plots show a positive slope with increasing sliding speed. PS generated a coarser surface roughness due to the removal of the soap film by the continuous rubbing of the contact surfaces. The destruction of this soap film caused greater metal-to-metal contact and generated deeper scratches on the pin surface. This phenomenon was related to the oxidation process that occurred on the metal surfaces because the unsaturated fatty acid in PS easily absorbed oxygen and hence, affected the reactions within the lubricant [28]. When oxidation occurs, there is a high tendency for the formation of deposits, which will cause deeper scratches on the pin surface. In addition, Autay et al. explained that wear debris essentially has an abrasive action, but its chemical composition is responsible for the presence of oxides [22]. The wear debris was embedded on the pin surface, thus increasing the surface roughness value.

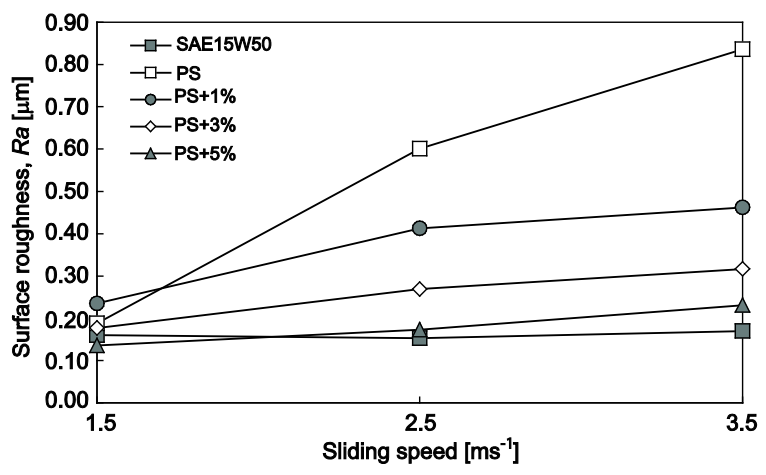

Fig. 4. Effects of sliding speed on surface roughness

The addition of ZDDP into PS had a positive effect on the surface protection, where PS produced a smoother surface with an increase in the ZDDP concentration. Fig. 4 shows PS with 5 wt $\%$ ZDDP additive only had a similar surface roughness with SAE15W50 at a sliding speed of $1.5 \mathrm{~ms}^{-1}$. At this sliding speed condition, the addition of $1 \mathrm{wt} \%$ ZDDP increased the surface roughness of PS, but the surface roughness of the pin became smoother as the concentration of ZDDP increased. Meanwhile, at sliding speeds of $2.5 \mathrm{~ms}^{-1}$ and $3.5 \mathrm{~ms}^{-1}$, the surface roughness was reduced as the ZDDP concentration increased. The presence of ZDDP in the PS contributed to the prevention of rapid oxidation, hence minimizing the rate of the removal of the soap film, resulting in a smoother surface.

\subsubsection{Worn Wear Surface Characteristics}

Further confirmation of the wear behaviour of the pin surfaces lubricated with commercial semi-synthetic oil and RBD palm stearin with and without additive was obtained by analysing the wear worn surface. Both the worn wear surface and slider profile of the pins were taken by using a high-resolution microscope. Figs. 5 to 7 show the worn wear surfaces and the surface profile of the rubbing surfaces lubricated with a commercial semi-synthetic oil (SAE15W50), an RBD palm stearin (PS), PS $+1 \mathrm{wt} \%$ ZDDP, PS $+3 \mathrm{wt} \%$ ZDDP and PS $+5 \mathrm{wt} \%$ ZDDP at various sliding speeds $\left(1.5 \mathrm{~ms}^{-1}\right.$, $2.5 \mathrm{~ms}^{-1}$ and $3.5 \mathrm{~ms}^{-1}$ ), respectively. The surface slider profile corroborates the $\mathrm{COF}$, where the steeper peak means that there is a larger amount of material removed. This also represents a deeper abrasive groove on the worn surface of the pin specimen.

It was observed that at all speed conditions, the PS generated deeper scratches on the worn surfaces and severe wear occurred at sliding speeds of $2.5 \mathrm{~ms}^{-1}$ and $3.5 \mathrm{~ms}^{-1}$. The darker region on the pin surface represents the oxidation. These deep scratches were apparently caused by the breakdown of the lubricant film, which was probably due to the occurrence of oxidation on the metal surfaces. This oxidation will eventually weaken the metal surface and cause more material to be removed. The ZDDP additive helped to overcome this problem by acting as an antioxidant agent in PS. With increasing ZDDP concentrations, less abrasive grooves appeared on the worn surfaces. The presence of ZDDP made the PS more resistant to oxidation; therefore, it had a lesser tendency to cause the removal of more material. It is evident that ZDDP effectively formed a lubricant film, which protected the metal surface from rapid oxidation, thus resulting in less material removal and smoother worn surfaces. This phenomenon was confirmed by the results of the friction and surface roughness measurement. It was shown that increasing the ZDDP concentrations reduced both the $\mathrm{COF}$ and surface roughness values. 

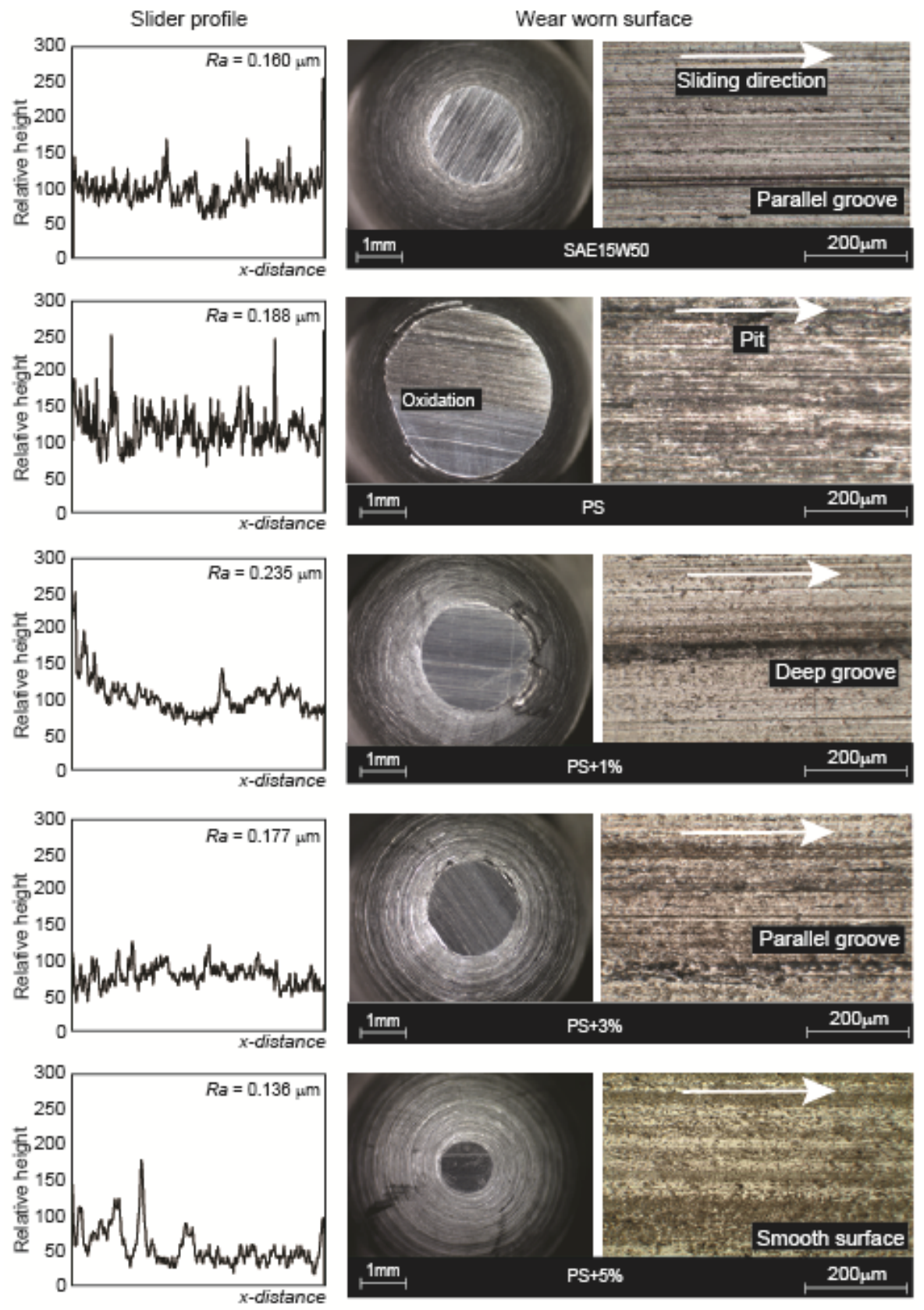

Fig. 5. Worn wear surfaces and surface profile under $1.5 \mathrm{~ms}^{-1}$ sliding speed

\section{CONCLUSIONS}

The lubrication performance of RBD palm stearin with and without ZDDP additive have been evaluated using a pin-on-disk tribotester. Commercial semi-synthetic oil (SAE15W50) was used for comparison purposes. The result shows that without ZDDP additive, RBD palm stearin generated a larger coefficient of friction and wear scar diameter than that of SAE15W50. The presence of a ZDDP additive in an RBD palm stearin improves both the friction-reducing and antiwear properties of the lubricant, where an increase in ZDDP concentrations improves both properties. An RBD palm stearin with a $5 \mathrm{wt} \%$ ZDDP additive shows a lower coefficient of friction compared to that of an SAE15W50 at various sliding speeds, but it creates a slightly larger wear scar diameter and rougher pin surfaces. In addition, surface wear analysis with an optical microscope shows abrasive wear as the dominant wear mechanism for both with 

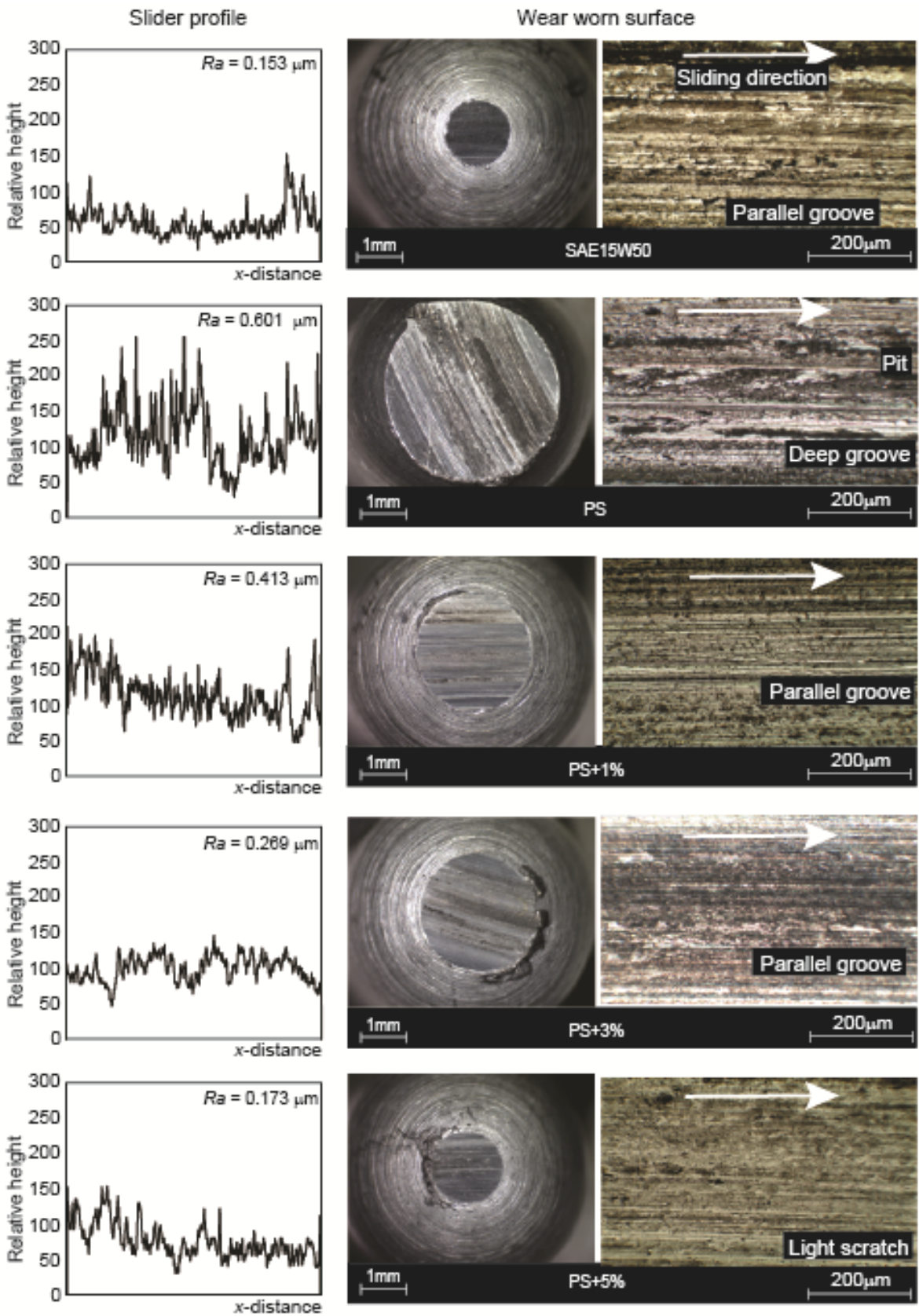

Fig. 6. Worn wear surfaces and surface profile under $2.5 \mathrm{~ms}^{-1}$ sliding speed

and without a ZDDP additive in an RBD palm stearin and SAE15W50. A pure RBD palm stearin shows that oxidation occurs, which is represented by the existence of a darker region on the worn surfaces. An increase in ZDDP concentrations showed less abrasive grooves appeared on the worn surfaces. In the present research, commercial semi-synthetic oil (SAE15W50) was used for comparison purposes to ensure that vegetable based oil formulations provide at least the same tribological performance as engine oil formulation for automotive applications. However, there is still a need to examine other properties such as oxidative and thermal stability of the formulated RBD palm stearin to be a competitive lubricant in automotive applications. Future work should be undertaken to investigate the oxidative and thermal stability of the formulated RBD palm stearin. 

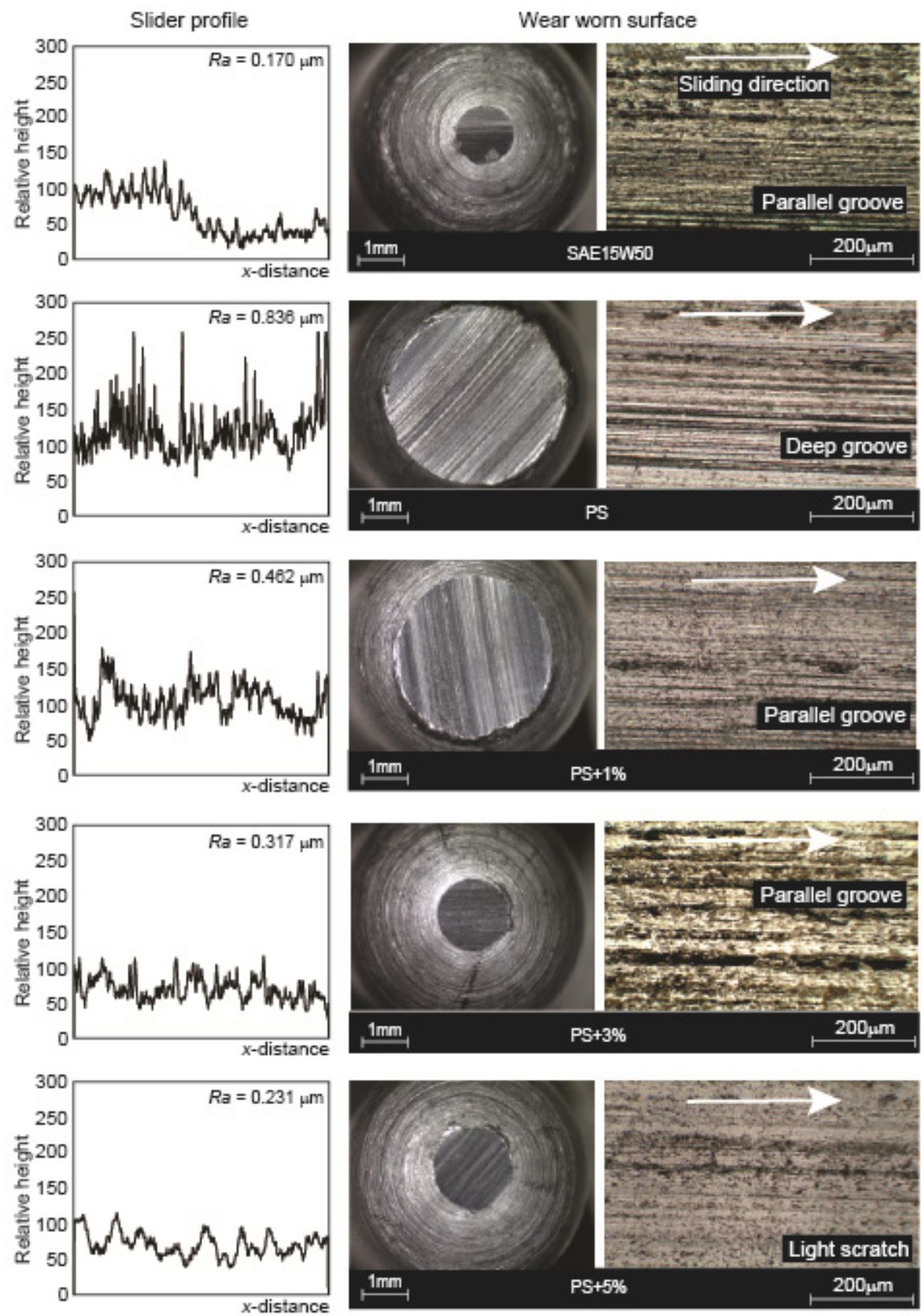

Fig. 7. Worn wear surfaces and surface profile under $3.5 \mathrm{~ms}^{-1}$ sliding speed

\section{ACKNOWLEDGEMENTS}

The authors wish to thank the Faculty of Mechanical Engineering at the Universiti Teknologi Malaysia for their support and cooperation during this study. The authors also wish to thank the Research Management Centre (RMC) for the Research University Grant (02G34, 02G35, 09H64) from the Universiti Teknologi Malaysia and Fundamental Research Grant Scheme
(4F610) from the Ministry of Higher Education for their financial support.

\section{REFERENCES}

[1] Joseph, P.V., Saxena, D., Sharma, D.K. (2007). Study of some non-edible vegetable oils of Indian origin for lubricant application. Journal of Synthetic Lubrication, vol. 24, no. 4, p. 181-197, D0I:10.1002/jsl.39. 
[2] Nagendramma, P., Kaul, S. (2012). Development of ecofriendly/biodegradable lubricants: An overview. Renewable and Sustainable Energy Reviews, vol. 16, no. 1, p. 764-774, Dol:10.1016/j.rser.2011.09.002.

[3] Chiong Ing, T., Rafiq, A.K.M., Azli, Y., Syahrullail, S. (2012). Tribological behaviour of refined bleached and deodorized palm olein in different loads using a four-ball tribotester. Scientia Iranica, vol. 19, no. 6, p.1487-1492, D0l:10.1016/j. scient.2012.10.027.

[4] Syahrullail, S., Azwadi, C.S.N., Ing, T.C. (2011). The metal flow evaluation of billet extruded with RBD palm stearin. International Review of Mechanical Engineering, vol. 5, no. 1, p. 21-27.

[5] Shahabuddin, M., Masjuki, H.H., Kalam, M.A., Bhuiya, M.M.K., Mehat, H. (2013). Comparative tribological investigation of bio-lubricant formulated from a non-edible oil source (Jatropha oil). Industrial Crops and Products, vol. 47, p. 323-330, DOl:10.1016/J.indcrop.2013.03.026.

[6] Erhan, S.Z., Sharma, B.K., Liu, Z., Adhvaryu, A. (2008). Lubricant base stock potential of chemically modified vegetable oils. Journal of Agricultural and Food Chemistry, vol. 56, no. 19, p. 8919-8925, D0l:10.1021/jf801463d.

[7] Jayadas, N.H., Prabhakaran Nair, K., Ajithkumar, G. (2007). Tribological evaluation of coconut oil as an environmentfriendly lubricant. Tribology International, vol. 40, no. 2, p. 350-354, D0l:10.1016/j.triboint.2005.09.021.

[8] Cheenkachorn, K. (2013). A study of wear properties of different soybean oils. Energy Procedia, vol. 42, p. 633-639, DOI:10.1016/j.egypro.2013.11.065.

[9] Mahipal, D., Krishnanunni, P., Rafeekh, M.P., Jayadas, N.H. (2014). Analysis of lubrication properties of zinc-dialkyl-dithiophosphate (ZDDP) additive on Karanja oil (Pongamia pinnatta) as a green lubricant. International Journal of Engineering Research, vol. 3, no. 8, p. 494-496, D0l:10.17950/ijer/ v3s8/804.

[10] Girotti, G., Raimondi, A., Blengini, G.A., Fino, D. (2011). The contribution of lube additives to the life cycle impacts of fully formulated petroleum-based lubricants. American Journal of Applied Science, vol. 8, no. 11, p. 1232-1240, D0l:10.3844/ ajassp.2011.1232.1240.

[11] Garcés, R., Martínez-Force, E., Salas, J.J. (2011). Vegetable oil basestocks for lubricants. Grasas y Aceites, vol. 62, no. 1, p. 21-28, D0I:10.3989/gya.045210.

[12] Fajdiga, G. (2015). Computational fatigue analysis of contacting mechanical elements. Tehnički vjesnik - Technical Gazette, vol. 22, no. 1, p. 169-175, D0l:10.17559/TV20140429122305.

[13] Blau, P.J. (2008). Friction Science and Technology from Concept to Applications. Taylor and Francis Group, United States, DOI:10.1201/9781420054101.

[14] Nuraliza, N., Syahrullail, S. (2016). Tribological effects of vegetable oil as alternative lubricant: A pin-on-disk tribometer and wear. Tribology Transactions, vol. 59, no. 5, p. 831-837, DOI:10.1080/10402004.2015.1108477.

[15] Miller, W.S., Zhuang, L., Bottema, J., Wittebrood, A.J., De Smet, P., Haszler, A., Vieregge, A. (2000). Recent development in aluminium alloys for the automotive industry. Materials
Science and Engineering: A, vol. 280, no. 1, p. 37-49, DOI:10.1016/S0921-5093(99)00653-X.

[16] Chawan, A.D., Chakravartula, A.M., Zhou, J., Pruitt, L.A., Ries, M., Komvopoulos, K. (2002). Effects of counterface roughness and conformity on the tribological performance of crosslinked and non-crosslinked medical-grade ultra-high molecular weight polyethylene. Materials Research Society Symposium Proceedings, vol. 724, p. 95-100, D0l:10.1557/ PROC-724-N5.10.

[17] Kabir, M.A., Higgs, C.F., Lovell, M.R. (2008). A pin-ondisk experimental study on a green particulate-fluid lubricant. Journal of Tribology, vol. 130, no. 4, p. 041801 , Dol:10.1115/1.2908913.

[18] Zulkifli, N.W.M., Masjuki, H.H., Kalam, M.A., Yunus, R., Azman, S.S.N. (2014). Lubricity of bio-based lubricant derived from chemically modified jatropha methyl ester. Jurnal Tribologi, vol. 1, p. 18-39.

[19] Oğuz, H., Düzcükoğlu, H., Ekinci, Ş. (2011). The investigation of lubrication properties performance of euro-diesel and biodiesel. Tribology Transactions, vol. 54, no. 3, p. 449-456, DOI:10.1080/10402004.2011.556315.

[20] Chen, C., Bosse, H., Deters, L. (2009). Effects of various base oils and additives on the tribological behaviour of lubricated aluminium- on-aluminium and steel-on-aluminium contacts. Proceedings of the Institution of Mechanical Engineers, Part J: Journal of Engineering Tribology, vol. 223, no. 3, p. 571-580, DOI:10.1243/13506501JET511.

[21] Joseph, P.V., Sharma, D.K. (2010). Improvement of thermooxidative stability of non-edible vegetable oils of indian origin for biodegradable lubricant application. Lubrication Science, vol. 22, no. 4, p. 149-161, Dol:10.1002/Is.116.

[22] Autay, R., Kchaou, M., Dammak, F. (2012). Friction and wear behavior of steels under different reciprocating sliding conditions. Tribology Transactions, vol. 55, no. 5, p. 590-598, DOI:10.1080/10402004.2012.684427.

[23] Barnes, A.M., Bartle, K.D., Thibon, V.R.A. (2001). A Review of zinc dialkyldithiophosphates (ZDDPS): characterisation and role in the lubricating oil. Tribology International, vol. 34, no. 6, p. 389-395, DOI:10.1016/S0301-679X(01)00028-7.

[24] Rohatgi, P.K., Tabandeh-Khorshid, M., Omrani, E., Lovell, M.R., Menezes, P.L. (2013). Tribology for Scientists and Engineers. p. 294-340, Springer, New York.

[25] Gunes, I., Uygunoglu, T., Erdogan, M. (2015). Effect of sintering duration on some properties of pure magnesium. Powder Metallurgy and Metal Ceramics, vol. 54, no. 3, p. 156-165, D0l:10.1007/s11106-015-9693-8.

[26] Syahrullail, S., Ismail, M.S.J. (2013). Lubrication performance of double fraction palm olein using pin-on-disk tribotester. IOP Conference Series: Materials Science and Engineering, vol. 50, no. 1, p. 012002, Dol:10.1088/1757-899X/50/1/012002.

[27] de Almeida, S.C.A., Belchior, C.R., Nascimento, M.V.G., Veira, L. dos S.R., Fleury, G. (2002). Performance of a diesel generator fuelled with palm oil. Fuel, vol. 81, no. 16, p. 2097-2102, D0I:10.1016/S0016-2361(02)00155-2.

[28] Masjuki, H.H., Maleque, M.A. (1996). The effect of palm oil diesel fuel contaminated lubricant on sliding wear of cast irons against mild steel. Wear, vol. 198, no. 1-2, p. 293-299, DOI:10.1016/0043-1648(96)07208-0. 